\title{
Influence of fibre orientation on cutting force in up and down milling of UD-CFRP composites
}

\author{
Norbert Geier ${ }^{1}$ \\ Received: 15 May 2020 / Accepted: 24 September 2020 / Published online: 6 October 2020 \\ (C) The Author(s) 2020
}

\begin{abstract}
Machining of carbon fibre reinforced polymer (CFRP) composites is extremely difficult, mainly due to their inhomogeneous and anisotropic properties. Predicting of cutting force during machining of CFRP is also difficult because the machinability properties of the composite are significantly orientation-dependent (fibre and machining directions). The main objective of the present study is to analyse the influence of fibre orientation on cutting force in milling of unidirectional CFRP. Up and down milling experiences were conducted based on a full factorial design. Experimental data were processed by fast Fourier transformation, regression analysis, and graphical adequate analysis. Multiple-order polynomial models were developed in order to minimise cutting force. Experimental results show that fibre orientation angle significantly influences the cutting force; furthermore, it does not have a significant effect on the passive force component, while the radial force component is more sensitive to the fibre orientation at up milling, than at down milling. An optimal condition is recommended for zig-zag milling of unidirectional CFRPs.
\end{abstract}

Keywords CFRP $\cdot$ Machining $\cdot$ Cutting force $\cdot$ Fibre orientation $\cdot$ Milling

Nomenclatu
$F(\mathrm{~N})$
$F_{f}(\mathrm{~N})$
$F_{p}(\mathrm{~N})$
$F_{r}(\mathrm{~N})$
$k(1)$
$n($ rpm $)$
$s($ act.
$v_{c}(\mathrm{~m} / \mathrm{min})$
$v_{f}(\mathrm{~mm} / \mathrm{min})$
$\alpha\left({ }^{\circ}\right)$
$\gamma\left({ }^{\circ}\right)$
$\delta\left(^{\circ}\right)$
$\theta\left(^{\circ}\right)$
$\phi\left({ }^{\circ}\right)$
$\mathrm{CFRP}$
$\operatorname{deg}$

Norbert Geier

geier@manuf.bme.hu

$1 \quad$ Faculty of Mechanical Engineering, Department of Manufacturing Science and Engineering, Budapest University of Technology and Economics, Budapest, Hungary

$\begin{array}{ll}E & \text { Expected value } \\ \text { ME } & \text { Main effect } \\ \text { UD } & \text { Unidirectional }\end{array}$

\section{Introduction}

Carbon fibre-reinforced polymer (CFRP) composite materials are favoured due to their excellent specific mechanical properties in industries where low weight and high strength are required $[1,2]$. For example, almost $50 \%$ of the structural elements of the Boeing 787 airliner consist of composite materials [3]. By using the novel composites, engineers were able to achieve $20 \%$ weight loss and $35 \%$ maintenance time reduction over previous models (Boeing 767 and 777). In the aerospace industry, as well as in the automotive, wind turbine, military, sports, and aerospace industries, manufacturers strive to laminate CFRP components in a single operation (moulding and hardening); however, they often require further processing before they can be used or assembled [4-6]. These may include (i) removing material build-up in the dividing plane of the laminating tool, (ii) removing excess material from the flange of the laminating tools, (iii) smoothing the mating surfaces of the laminated composites, and (iv) making 
holes for assembly of components [7-9]. Typically, these post-manufacturing needs are met by various machining techniques, like conventional drilling, helical milling, tilted helical milling, wobble milling, side milling, or edge trimming $[6$, $10-13]$.

Nevertheless, the cutting of CFRP composite materials is complicated and expensive: (i) due to the inhomogeneity and anisotropy of the material, the characteristic geometrical errors caused by the machining and the chip formation mechanisms are significantly dependent on the machining directions; (ii) carbon fibres have a strong abrasive wear effect, which should be considered for the cutting tool and for the machine tool also; and (iii) heat dissipation is also problematic due to the low thermal conductivity of polymers and the dangers of using coolant lubricants (polymer wicking) [2, 4-6, 14, 15]. Because of these cutting features and conditions, CFRP materials are referred to as difficult-to-cut materials, which can result in a variety of micro- and macro-geometric material defects like delamination, uncut fibres, matrix burning, fibre pull-outs, or micro-cracking [13, 16-26]. Although centuries of experience in the field of metalworking have been accumulated, this theoretical and practical knowledge cannot be directly applied to the cutting science of fibre-reinforced technical polymer composite materials that have been researched for only a few decades.

Investigation of cutting forces are often unavoidable for modelling (i) tool wear, (ii) chip forming mechanisms, (iii) micro-, and (iv) macro-geometric errors caused by machining [27-29]. The mechanical and thermodynamic properties of quasi-homogeneous materials are quasi-isotropic so that the machinability properties are less directional [30-34]. However, this is not true for a fibre reinforced composite material [35], the machinability of fibre-reinforced materials is therefore strongly direction-dependent. In this paper, the effect of the fibre orientation angle $(\phi$ - the angle between the direction of the fibres and the vector of the feed rate, as illustrated in Fig. 1) is investigated on the cutting force $(F)$, which describes the direction dependence of the composite. Cutting force dependence on the fibre orientation angle is discussed already in some key papers [36-40]; however, there are still many lacks of knowledge in cutting force optimisation in UD-CFRP in the case of up and down milling.

Li et al. [36] carried out orthogonal machining experiments in unidirectional CFRP composite and found that the effect of the fibre cutting angle $(\theta$ - angle between the direction of the fibres and the vector of the cutting speed, as illustrated in Fig. 1) and the depth of cut are significant on the cutting force and their interaction effect is also significant. Voss et al. [37] analysed the influence of fibre orientation on the cutting force and on the quality of machined features in milling CFRP. They observed that fibre cutting angle has a significant effect on cutting force and on surface quality. They showed that cutting force can be decreased by increasing the rake and the

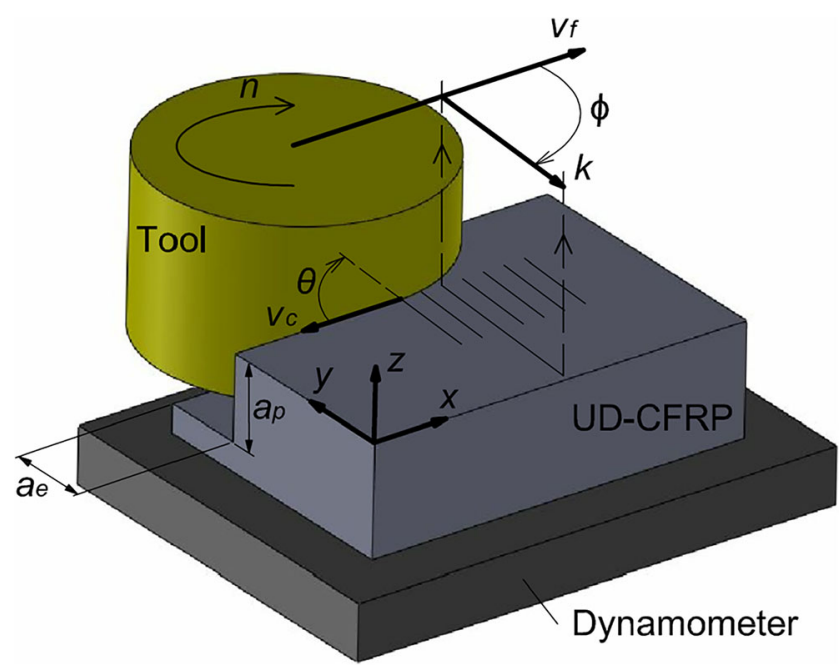

Fig. 1 The schematics of the experimental setup (climb milling), where $k$ denotes the direction of fibre reinforcements, $v_{f}$ is the feed rate, $v_{c}$ is the cutting speed, $a_{p}$ is the depth of cut, $a_{e}$ is the cutting width, $n$ is the spindle speed, $\phi$ is the fibre orientation angle, and $\theta$ is the fibre cutting angle

clearance angles; furthermore, optimal cutting process parameters were defined to maximise machining quality and minimise cutting force. Li et al. [41] analysed the machinability of UD-CFRP by up milling experiments and concluded that there is a strong correlation between surface roughness and vibration of cutting force signals. Furthermore, they showed that the fibre orientation angle has a significant effect on the cutting force. Xu et al. [42] conducted machining experiments in CFRP and proved that the feed rate has the most significant influence on the cutting force that closely correlates with delamination and burr formation. They confirmed and validated these findings in Xu et al. [43] too.

Wang et al. [44] analysed the influence of fibre cutting angle on the cutting force components in milling UD-CFRP with a small radial depth of cut of $\left(a_{e}=0.1 \mathrm{~mm}\right)$. They observed that the radial cutting force is the most effected by the fibre cutting angle, followed by the tangential force, while the passive force component is less influenced by the $\theta$. He et al. [38] investigated the cutting force in slot milling of CFRP using a two-straight-flute carbide mill. They resulted that fibre cutting angle of $\theta=135^{\circ}$ causes the largest tangential forces and specific energies, while the tangential cutting force at $\theta=$ $45^{\circ}$ is the smallest. Wang et al. [45] conducted milling experiments in CFRP and analysed the influences of process parameters on the cutting force using response surface methodology. They proved that feed rate has the most significant effect on cutting force, followed by the cutting speed and the radial depth of cut. Sui and Wang [39] conducted slot milling experiments in UD-CFRP. They proved that the cutting speed has only just a little effect on the cutting force, while the effect of fibre orientation and chip thickness is significant on it. The total machining power should be kept in minimal in order to improve the flexural strength of CFRP and improve the quality of machined features; according to Ashworth et al. [8], the 
minimisation of cutting force is therefore relevant and necessary.

Modelling of cutting forces in orthogonal cutting of CFRP composites are often based on laws of physic (e.g., Kienzle model) $[46,47]$. Nevertheless, in the case of more complex technologies like drilling or milling processes, cutting forces are often modelled by statistic, semi-mechanistic, or numerical techniques [48, 49]. Each modelling approaches have their advantages and limitations, which have to be addressed before selecting them. Mechanistic models have a physical aspect which enables to understand the analysed process; however, it is extremely difficult to use them to model complex systems or processes (advanced shaped tools, difficult tool path or non-homogeneous materials etc.). In contrast, the physical meaning of statistical models is strongly limited, but they are often preferred in recent cutting-edge-research areas like in smart manufacturing, self-organisation, intelligent machining, digital twin or real-time process monitoring, and diagnostics solutions [50]. Polynomial models are often preferred in these sectors because it is easy and fast to calculate with these formulas by computers, even in quasi-real-time.

Although experimental and simulation studies and modelling of cutting forces have been addressed in many of scientific studies, only a few papers have been published on the effect of up and down milling strategies on cutting forces. Moreover, it is not possible to clearly derive from these articles the knowledge required to create (i) a special (tilted) trochoidal toolpath for, e.g. efficient slotting, or (ii) an optimised zig-zag (up and down alternately) type toolpath for CFRP milling. Therefore, the main objective of the present experimental study was to analyse the influence of the fibre orientation on the cutting force in climb (down) and conventional (up) milling of unidirectional carbon fibre reinforced polymer (UD-CFRP) composites. The other main goal was to develop an adequate polynomial model that is capable of force optimisation.

The rest of the paper is organised as follows: First, the experimental setup is introduced; then, the experimental results are presented. Finally, the results are compared and discussed based on the analysis of chip removal mechanisms.

\section{Experimental setup}

Edge milling experiments were performed in a hand lay-up laminated, epoxy resin-based unidirectional CFRP composite. The ratio of the applied FM20 resin to the MH3124 hardener was 100:35, respectively, while the reinforcement was a dry unidirectional carbon fibre fabric. The thickness of the laminate was $t=25 \mathrm{~mm}$. The important mechanical properties (tensile strength, interlaminar shear, hardness, and impact strength) of the applied composite are measured by using a Zwick Z250 and a Zwick Z020 tensile testers, a Zwick
H04.3150 hardness tester, and a Ceast Resil Impact Junior impact tester, respectively. The measurement setups were repeated five times, and the average and the deviations were calculated, as summarised in Table 1.

The machining experiments were conducted on a VF 22 vertical spindle milling machine. The chips were removed from the cutting zone with a NILFISK GB733 industrial vacuum cleaner. Coolant lubricant was not used for the experiments (dry machining). An uncoated HSS end mill with a diameter of $D=\varnothing 50 \mathrm{~mm}$, with $z=5$ cutting edges (clearance angle of $\alpha=10^{\circ}$, rake angle of $\gamma=25^{\circ}$, and helix angle of $\lambda=$ $40^{\circ}$ ) was used for the milling experiments. The machining experiments were designed using the full factorial experiment design method. The factors and their levels are shown in Table 2. The 4th level $\left(\phi=90^{\circ}\right)$ was repeated five times in order to calculate reproducibility deviation for regression analysis and graphical adequate analysis.

The values of the technological parameters not listed in the table were fixed in order to fix their influences on the cutting force, as follows: cutting speed of $v_{c}=230 \mathrm{~m} / \mathrm{min}$, feed rate of $v_{f}=397 \mathrm{~mm} / \mathrm{min}$ (feed per tooth of $f_{z}=0.054 \mathrm{~mm} /$ tooth), axial depth of cut of $a_{p}=7 \mathrm{~mm}$, and radial depth of cut of $a_{e}=$ $3 \mathrm{~mm}$. The schematic drawing of the experimental milling setup can be seen in Fig. 1.

Cutting force was measured with a KISTLER 9281B threecomponent dynamometer, and collected using a LabVIEW measurement program at a sampling frequency of $f_{m}=$ $18,000 \mathrm{~Hz}$ for $t=10 \mathrm{~s}$ per experimental setting. The spindle of the milling machine was equipped by an eccentric switch (a metal element), which position was detected by an OMRON E3F-DS10B4 proximity sensor, in each spindle rotations. The force data and the data provided by the proximity sensor was collected simultaneously, the exact position of the cutting edges could be therefore determined.

The analysis of tool wear is not in the scope of this study, however, it had to be monitored in order to minimise its influence on the analysed response variables. The tool wear criterion was defined in a maximum of $V B=0.3 \mathrm{~mm}$ wear in length, measured from the tip of the tool edges on the clearance face of the tool edges. The tool wear was measured by digital image processing of pictures provided by a Dino-Lite AD7013MZT digital microscope. Images were collected after each experimental setup. The tool wear on the clearance surface did not reach the defined tool wear criterion, the tool wear therefore not influences significantly the experimental results

Table 1 Main mechanical properties of the applied unidirectional CFRP

\begin{tabular}{lllc}
\hline Tensile strength & $\sigma$ & $\mathrm{MPa}$ & $723.00 \pm 58.29$ \\
Interlaminar shear & $\tau$ & $\mathrm{MPa}$ & $19.26 \pm 0.76$ \\
Shore $D$ hardness & $S_{D}$ & - & $85.5 \pm 1.9$ \\
Charpy impact strength & $C$ & $\mathrm{KJ} / \mathrm{m}^{2}$ & $203.18 \pm 31.38$ \\
\hline
\end{tabular}


Table 2 Factors and their levels

\begin{tabular}{lllllll}
\hline Factors & \multicolumn{2}{l}{ Levels } & & & & \\
\cline { 2 - 5 } & 1 & 2 & 3 & 4 & 5 & 6 \\
\hline Fibre orientation angle $\left(^{\circ}\right)$ & 0 & 30 & 60 & 90 & 120 & 150 \\
Strategy $(-)$ & Down & $\mathrm{Up}$ & & & & \\
\hline
\end{tabular}

of this study. Representative images of clearance faces of the cutting tool is shown in Fig. 2.

\section{Applied methods and techniques}

The collected force signal is noisy mostly due to the tool vibration, the filtering of data is therefore often necessary. Frequency filtering was applied at the measured force values using the fast Fourier transformation (FFT) and a Butterworth low pass filter with a cut-off frequency of $f_{c}=400 \mathrm{~Hz}$ (cutting edges enter the workpiece at the frequency of $f=$ $\left.1000 v_{c} z(D \pi)^{-1} \approx 122 \mathrm{~Hz}\right)$. The principle of applied frequency filtering is illustrated in Fig. 3. The original force signal is first transformed by using the FFT, then the Butterworth filters the high-frequency signals, then the spectrum is inverse transformed by inverse FFT.

The main steps of optimisation parameter calculations are, as follows: (i) selecting an evaluation period $t_{k}=1 \mathrm{~s}$ in the filtered force diagram (Fig. 3), during which the tool continuously machines, then (ii) dividing the evaluation phase into $m=10$ equal subsections, and then (iii) calculating the maximal parameter in each subsection ( $F_{f 1}$ in Fig. 3 ), finally (iv) averaging the features calculated in the subsections for the evaluation phase (based on Fig. 3: $F_{f}=10^{-1}\left(\sum F_{f i}\right)$ ). The resulting $F(\phi)$ force (cutting force) was calculated by Eq. (1).

$F(\phi)=\sqrt{F_{f}(\phi)^{2}+F_{r}(\phi)^{2}+F_{p}(\phi)^{2}}$

where $F$ denotes the cutting force, $\phi$ is the fibre orientation angle, while $f$ indicates the direction of the feed rate $(y$ in Fig. 1), $r$ indicates the radial direction ( $x$ in Fig. 1) and $p$ indicates the passive ( $z$ in Fig. 1 ) direction.
During the evaluation, polynomial models were fitted to the force parameters, and they were adequately examined by (i) regression analysis and (ii) graphical adequate analysis. If the R squared $\left(R^{2}\right)$ of the $d e g=1$ regression model was smaller than $R^{2}=0.9$, then the degree ( $d e g$ ) of the polynomial model was increased by $d e g=d e g+1$, until $R^{2} \geq 0.9$. A general $d e g=5$ polynomial model used here is expressed by Eq. (2).

$F(\phi)=f \phi^{5}+e \phi^{4}+d \phi^{3}+c \phi^{2}+b \phi+a$

where $F$ denotes the cutting force, $\phi$ is the fibre orientation angle, while $a, b, c, d, e$ and $f$ are regression coefficients. The results of the regression analysis are summarised in Table 3.

The reproducibility was determined by averaging the empirical standard deviation values obtained five times by repeating the experimental set-up of $\phi=90^{\circ}$, using Eq. (3).

$r=\frac{1}{n} \sum_{i=1}^{n} \sqrt{\frac{1}{m-1}\left[F_{i j}-\left(\frac{1}{m} \sum_{j=1}^{m} F_{i j}\right)\right]^{2}}$

where $n=5$ the number of repeated experimental settings, $m=10$ is the number of evaluation subsets, and $F$ is the value of the optimisation parameter determined by the filtered force diagram. The reproducibility standard deviation was used for graphical adequate analysis, as follows: (i) the error interval of the measured cutting force parameters are defined in $F=E(F)$ $\pm r$, (ii) a deg $=1$ polynomic is fitted to the force data (Fig. 4a), (iii) if the polynomic approximates worse than the $E(F) \pm r$ defined interval, then the degree of the polynomial model has to be increased: $\operatorname{deg}=\operatorname{deg}+1$, as illustrated in Fig. 4 . The graphical adequate analysis resulted in the same degree of polynomials as the regression analysis.

\section{Experimental results and discussion}

This section of the present study is comprised of three parts. First, the results of the cutting force of climb milling, then the results of the cutting force of conventional milling experiments are presented. Finally, the climb milling and conventional milling results are compared and discussed in detail, from the point of view chip removal mechanisms associated with different fibre cutting angles. a)

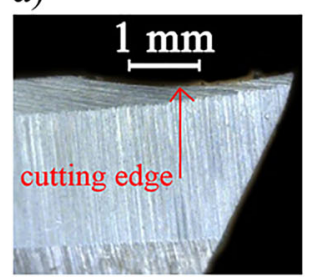

b)

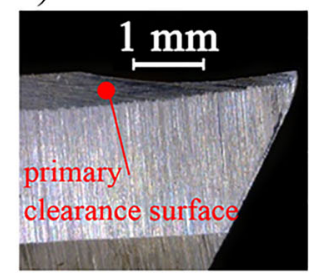

c)

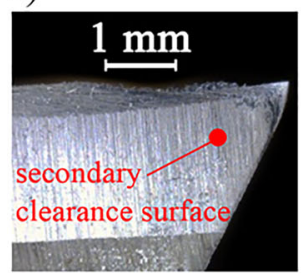

d)

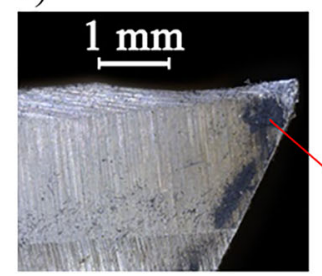

e)

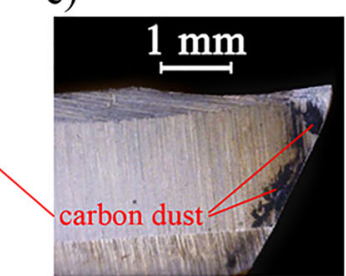

Fig. 2 Tool wear on the clearance surface of the no. 1 cutting edge: $\mathbf{a}$ before the experiments are started, $\mathbf{b}$ after the 6 th experimental setup, $\mathbf{c}$ after the 10th experimental setup, $\mathbf{d}$ after the 16th experimental setup, and $\mathbf{e}$ after the 20th experimental setup 
Fig. 3 Frequency filtering of measured force values using a low pass Butterworth filter: a generating a frequency spectrum using the FFT, $\mathbf{b}$ applying a Butterworth low pass filter, and $\mathbf{c}$ using the inverse FFT

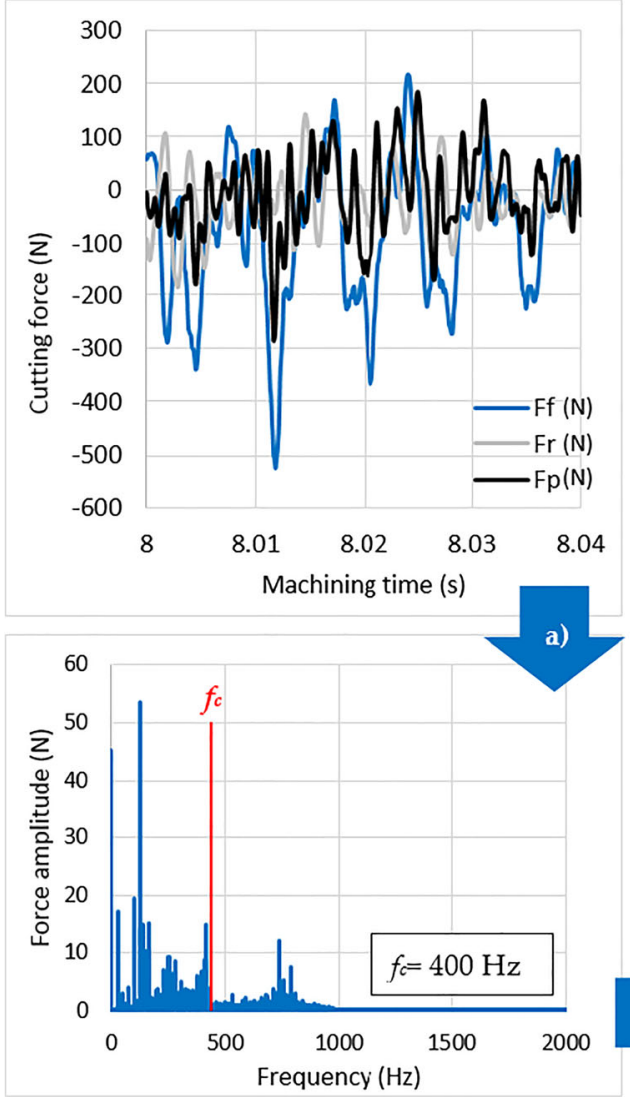

\subsection{Climb milling results}

Filtered cutting force diagrams in the case of climb (down) milling of unidirectional CFRP, can be seen in Fig. 5 . Diagrams show the main cutting force $(F)$ in the function of machining time. It can be clearly seen in the diagrams that the fibre orientation has a significant effect on the characteristics of cutting force. The maximal cutting force often reaches the $600-800 \mathrm{~N}$ values in the case of fibre orientation of $0^{\circ}, 30^{\circ}$, and $60^{\circ}$; however, its values are lower at higher fibre orientation angles.
The effect of the five cutting edges of the end mill can be clearly detected (local maximum points) in the case of lower fibre orientations, but at higher $\phi$, the characteristics of the force diagrams are more homogeneous. Its possible reason is that there is more signal noise on the lower cutting force data than on the higher ones. From the comparison of the results dedicated to fibre orientation angle of $\phi=0^{\circ}$ and $\phi=120^{\circ}$, it can be stated that the maximum of cutting forces significantly differences and the detecting ability of the local maximum points are also different due to the relative higher signal noise on the lower force data.

Table $3 \quad R^{2}$ for different degrees of polynomial models

\begin{tabular}{|c|c|c|c|c|c|c|c|c|}
\hline \multirow[t]{3}{*}{$\operatorname{Deg}(-)$} & \multicolumn{8}{|l|}{$R^{2}(-)$} \\
\hline & \multicolumn{4}{|c|}{ Climb (down) milling } & \multicolumn{4}{|c|}{ Conventional (up) milling } \\
\hline & $F$ & $F_{f}$ & $F_{r}$ & $F_{p}$ & $F$ & $F_{f}$ & $F_{r}$ & $F_{p}$ \\
\hline 1 & 0.1245 & 0.1244 & 0.0056 & 0.0001 & 0.2147 & 0.2332 & 0.1391 & 0.0068 \\
\hline 2 & 0.7004 & 0.6972 & 0.0411 & 0.2566 & 0.4933 & 0.4886 & 0.5137 & 0.8848 \\
\hline 3 & 0.9741 & 0.9714 & 0.0500 & 0.2735 & 0.9550 & 0.9670 & 0.8545 & 0.9142 \\
\hline 4 & 0.9776 & 0.9753 & 0.4508 & 0.6333 & 0.9662 & 0.9845 & 0.8570 & 0.9469 \\
\hline 5 & 0.9929 & 0.9913 & 0.9987 & 0.9099 & 0.9843 & 0.9907 & 0.9177 & 0.9924 \\
\hline 6 & 1.0000 & 1.0000 & 1.0000 & 1.0000 & 1.0000 & 1.0000 & 1.0000 & 1.0000 \\
\hline
\end{tabular}

Italics numbers denote the lower value of R squared than 0.9 , bold numbers denote the first higher value of $\mathrm{R}$ squared than 0.9 
Fig. 4 a The polynomial approximates worse than the $E(F) \pm r$ defined interval; the degree of the polynomial has to be therefore increased, where $\delta$ is the error of the approximation; $\mathbf{b}$ the polynomial approximates better than the $E(F) \pm r$ defined interval; the degree of the polynomial has to be therefore fixed.

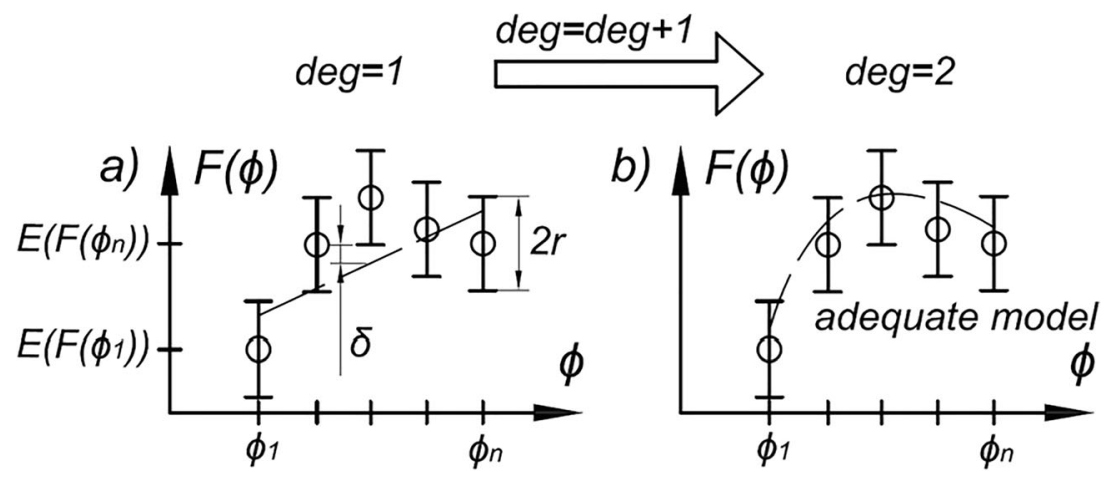

The quantitative results of climb milling experiments are listed in Table 4 and illustrated in the diagram in Fig. 6.

The effect of the fibre orientation angle on the feed force is significant (main effect of $F_{f}: M E\left(F_{f}\right)=473.55 \mathrm{~N}$ ), while the effect of the radial and passive forces is smaller $\left(M E\left(F_{r}\right)=\right.$ $\left.27.36 \mathrm{~N}, M E\left(F_{p}\right)=51.68 \mathrm{~N}\right)$. The main cutting force function for climb milling UD-CFRP is expressed in Eq. (4). The degree of the polynomials of the components of the cutting force is calculated by regression analysis (Table 3 ) and validated by graphical adequate analysis (Fig. 4).
$F_{\text {down }}(\phi)=\left[\begin{array}{c}F_{f}(\phi) \\ F_{r}(\phi) \\ F_{p}(\phi)\end{array}\right]=\left[\begin{array}{c}d_{f} \phi^{3}+c_{f} \phi^{2}+b_{f} \phi+b_{f} \\ f_{r} \phi^{5}+e_{r} \phi^{4}+d_{r} \phi^{3}+c_{r} \phi^{2}+b_{r} \phi+a_{r} \\ f_{p} \phi^{5}+e_{p} \phi^{4}+d_{p} \phi^{3}+c_{p} \phi^{2}+b_{p} \phi+a_{p}\end{array}\right], \phi \in(4)$

where index $f$ denotes the feed direction, index $r$ is the radial direction, and $p$ index is the passive direction, while indexes $a$, $b, c, d, e$, and $f$ denote the regression coefficients, the latter of which are shown in Table 5.

The function $F_{\text {down }}(\phi)$ has a minimum point, which should be used to design the cutting technology of laminated
Fig. 5 Filtered cutting force diagrams in the case of climb (down) milling of unidirectional CFRP at fixed process parameters of $v_{c}=230 \mathrm{~m} / \mathrm{min}, v_{f}=397 \mathrm{~mm} /$ $\min , a_{p}=7 \mathrm{~mm}$, and $a_{e}=3 \mathrm{~mm}$, but at different fibre orientation angles: $\mathbf{a} \phi=0^{\circ}, \mathbf{b} \phi=30^{\circ}, \mathbf{c} \phi=$ $60^{\circ}, \mathbf{d} \phi=90^{\circ}$, e $\phi=120^{\circ}$, and $\mathbf{f}$ $\phi=150^{\circ}$
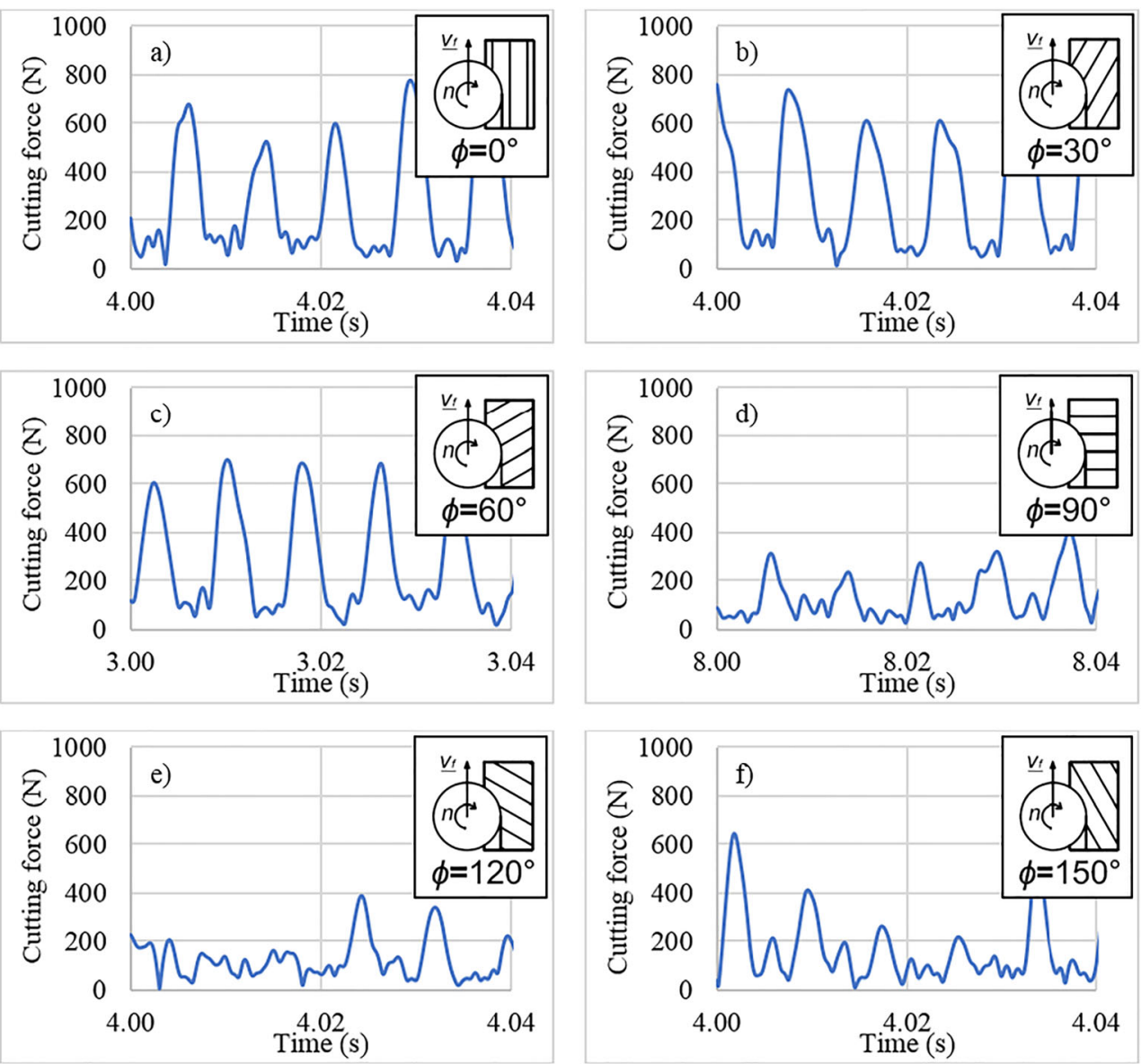
Table 4 Quantitative results of climb milling experiments in unidirectional CFRP

\begin{tabular}{|c|c|c|c|c|c|c|c|c|c|}
\hline No. (-) & $\phi\left(^{\circ}\right)$ & $F(\mathrm{~N})$ & $s F(\mathrm{~N})$ & $F_{f}(\mathrm{~N})$ & $s F_{f}(\mathrm{~N})$ & $F_{r}(\mathrm{~N})$ & $s F_{r}(\mathrm{~N})$ & $F_{p}(\mathrm{~N})$ & $s F_{p}(\mathrm{~N})$ \\
\hline 1 & 0 & 880.22 & 27.77 & 876.27 & 28.40 & 118.83 & 19.03 & 128.38 & 9.59 \\
\hline 2 & 30 & 834.77 & 21.65 & 830.39 & 22.60 & 126.35 & 9.14 & 124.46 & 12.83 \\
\hline 3 & 60 & 750.06 & 26.06 & 748.55 & 26.93 & 137.15 & 16.69 & 134.25 & 23.16 \\
\hline 4 & 90 & 406.97 & 33.82 & 388.20 & 31.33 & 111.93 & 14.70 & 160.83 & 11.83 \\
\hline 5 & 90 & 463.79 & 27.85 & 450.65 & 27.10 & 111.30 & 13.28 & 165.82 & 20.99 \\
\hline 6 & 90 & 474.08 & 26.73 & 459.63 & 27.08 & 107.95 & 16.40 & 158.86 & 16.03 \\
\hline 7 & 90 & 509.45 & 30.41 & 506.34 & 29.68 & 121.44 & 18.41 & 134.40 & 24.99 \\
\hline 8 & 90 & 548.54 & 29.34 & 541.64 & 27.42 & 142.45 & 19.83 & 109.96 & 18.13 \\
\hline 9 & 120 & 410.01 & 24.55 & 402.72 & 23.94 & 115.09 & 22.60 & 161.64 & 15.46 \\
\hline 10 & 150 & 548.54 & 29.34 & 541.64 & 27.42 & 142.45 & 19.83 & 109.96 & 18.13 \\
\hline
\end{tabular}

composite materials around this minimum point since these fibre orientation angles can reduce the cutting force and reduce (i) tool wear, (ii) workpiece heat shock, and (iii) delamination of the laminate layers. This force-minimum can be calculated by deriving the $F_{\text {down }}(\phi)$ function according to Eq. (5).

$$
\begin{aligned}
& \frac{d}{d \phi} F_{\text {down }}(\phi)=0 \stackrel{\text { choose }}{\rightarrow} \phi_{\text {min }}=123.33^{\circ} ; F_{\text {down }}\left(\phi_{\text {min }}\right) \\
& \quad=423.90 \mathrm{~N}
\end{aligned}
$$

For climb milling unidirectional CFRP, it is advisable to design the machining technology to a fibre orientation angle of $\phi_{\mathrm{opt}}=123^{\circ}$ in order to minimise cutting force.

\subsection{Conventional milling results}

Filtered cutting force diagrams in the case of conventional (up) milling of unidirectional CFRP, can be seen in Fig. 7. Diagrams show the main cutting force $(F)$ in the function of machining time. Similarly, to the results of the climb milling experiments, it can be clearly seen in the diagrams that the fibre orientation has a significant effect on the characteristics of cutting force. However, the maximal cutting force reaches $600-800 \mathrm{~N}$ values in the case of fibre orientation of $30^{\circ}$ and $60^{\circ}$. The fibre orientation of $150^{\circ}$ resulted in the lowest, while the fibre orientation of $60^{\circ}$ resulted in the highest maximum main cutting forces.

The quantitative results of up milling experiments are listed in Table 6 and illustrated in the diagram in Fig. 8. It can be seen in Fig. 8 that the effect of the fibre orientation angle on the feed directional cutting force component $\left(\operatorname{ME}\left(F_{f}\right)=\right.$ $570.74 \mathrm{~N}$ ) is the most significant, followed by the radial force component $\left(\mathrm{ME}\left(F_{r}\right)=364.26 \mathrm{~N}\right)$, while the effect on the passive force component is smaller $\left(\mathrm{ME}\left(F_{p}\right)=74.53 \mathrm{~N}\right)$.

The main cutting force function for up milling UD-CFRP is expressed in Eq. (6). The degree of the polynomials of the components of the cutting force is calculated by regression analysis (Table 3 ) and validated by graphical adequate analysis (Fig. 4).
Fig. 6 Influence of fibre orientation angle on the components of the cutting force in the case of climb milling unidirectional CFRP composite

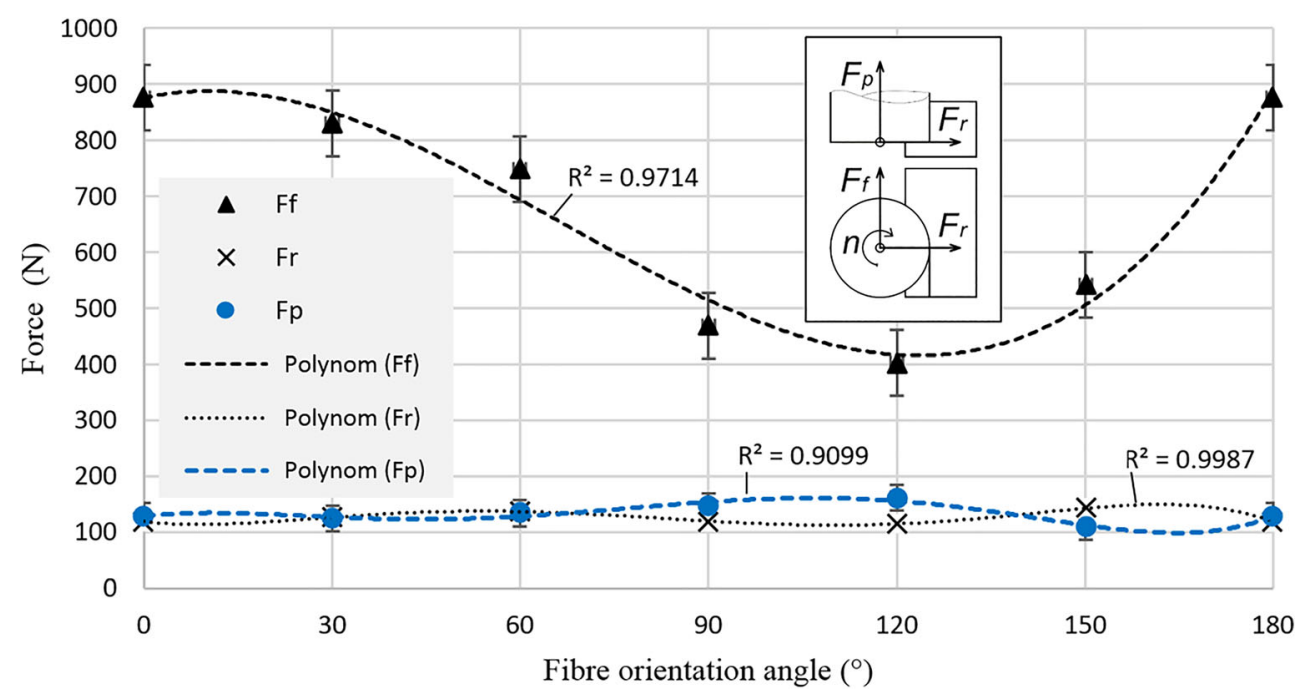


Table 5 Regression coefficients for the force models

\begin{tabular}{llrrr}
\hline Milling strategy & regression coefficient & $f$ (feed direction) & $r$ (radial direction) & $p$ (passive direction) \\
\hline Down milling & $a$ & 875.3112757143 & 118.7947112686 & 127.9808361169 \\
& $b$ & -2.4814705899 & -1.2691836483 & 1.3962226532 \\
& $c$ & 0.1308792066 & 0.0933816261 & -0.0915215036 \\
& $d$ & 0.0006528621 & -0.0017651494 & 0.0018365264 \\
& $e$ & 0.0000000000 & 0.0000125338 & -0.0000136347 \\
Up milling & $f$ & 0.0000000000 & -0.0000000300 & 0.0000000334 \\
& $a$ & 368.6456833334 & 254.6311364531 & 111.3035330952 \\
& $b$ & 22.6055071825 & -0.8008533404 & 2.0029893757 \\
& $c$ & -0.3054684577 & 0.4354408920 & -0.0166416251 \\
& $d$ & 0.0010010386 & -0.0085444421 & 0.0000312103 \\
& $e$ & 0.0000000000 & -0.0000001231 & 0.0000000000 \\
\hline$f$ & 0.0000000000 & 0.0000000000 \\
\hline
\end{tabular}

$F_{u p}(\varphi)=\left[\begin{array}{c}F_{f}(\phi) \\ F_{r}(\phi) \\ F_{p}(\phi)\end{array}\right]=\left[\begin{array}{c}d_{f} \phi^{3}+c_{f} \phi^{2}+b_{f} \phi+a_{f} \\ f_{r} \phi^{5}+e_{r} \phi^{4}+d_{r} \phi^{3}+c_{r} \phi^{2}+b_{r} \phi+a_{r} \\ d_{p} \phi^{3}+c_{p} \phi^{2}+b_{p} \phi+a_{p}\end{array}\right], \phi \in[0 ; 180)$

calculated by deriving the $F_{\text {up }}(\phi)$ function according to Eq. (7).

$$
\frac{d}{d \phi} F_{u p}(\phi)=0 \stackrel{\text { choose }}{\rightarrow} \phi_{\min }=155.59^{\circ} ; F_{u p}\left(\phi_{\min }\right)=316.51 \mathrm{~N}
$$

The values of regression coefficients are listed in Table 5 .

The function $F_{\text {up }}(\phi)$ has a minimum point, which can be

Fig. 7 Filtered cutting force diagrams in the case of conventional (up) milling of unidirectional CFRP at fixed process parameters of: $v_{c}=$ $230 \mathrm{~m} / \mathrm{min}, v_{f}=397 \mathrm{~mm} / \mathrm{min}$, $a_{p}=7 \mathrm{~mm}, a_{e}=3 \mathrm{~mm}$, but at different fibre orientation angles: $\mathbf{a} \phi=0^{\circ}, \mathbf{b} \phi=30^{\circ}, \mathbf{c} \phi=60^{\circ}, \mathbf{d}$ $\phi=90^{\circ}$, e $\phi=120^{\circ}$, and $\mathbf{f} \phi=$ $150^{\circ}$
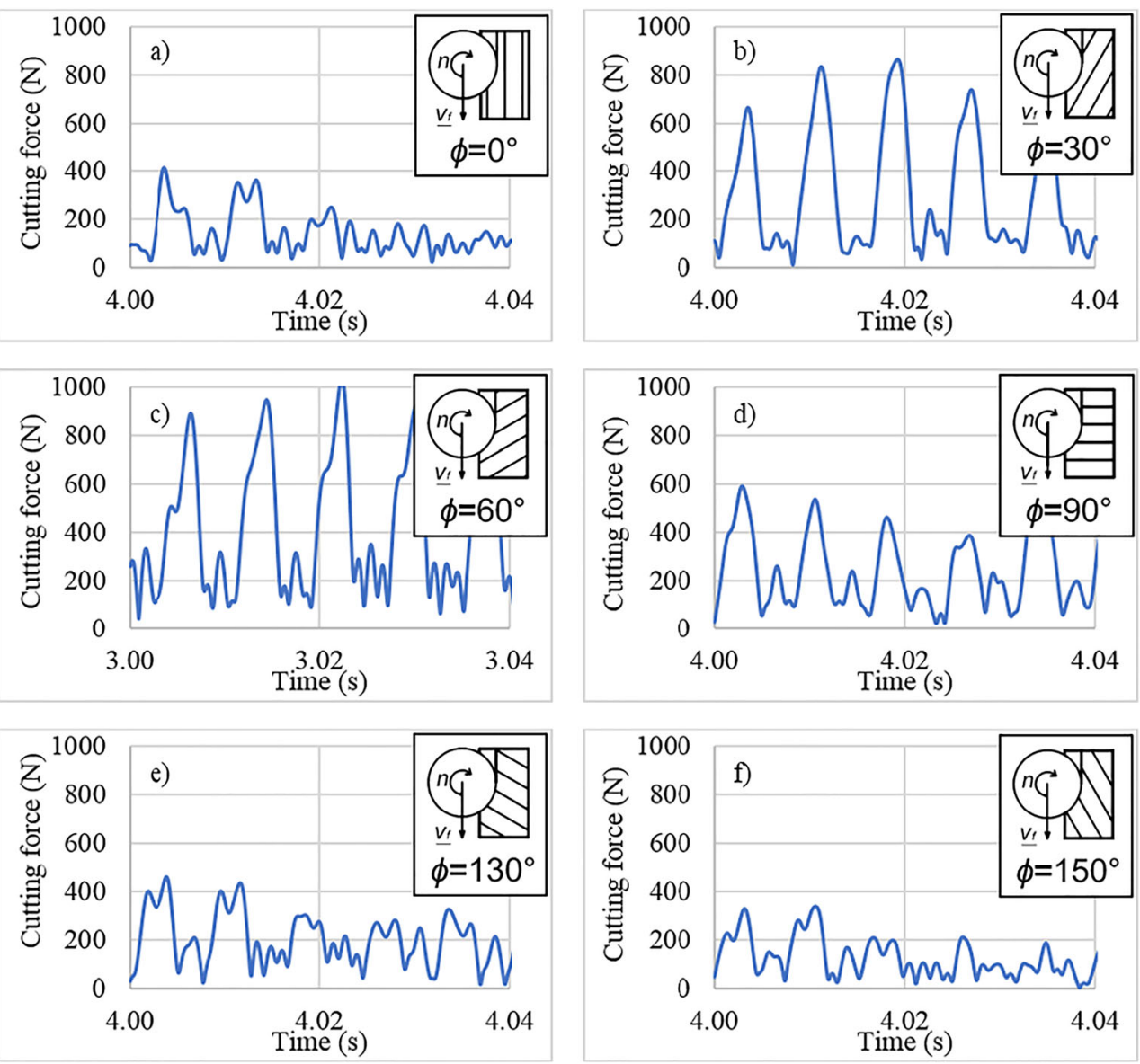
Table 6 Quantitative results of conventional milling experiments in unidirectional CFRP

\begin{tabular}{|c|c|c|c|c|c|c|c|c|c|}
\hline No. (-) & $\phi\left({ }^{\circ}\right)$ & $F(\mathrm{~N})$ & $s F(\mathrm{~N})$ & $F_{f}(\mathrm{~N})$ & $s F_{f}(\mathrm{~N})$ & $F_{r}(\mathrm{~N})$ & $s F_{r}(\mathrm{~N})$ & $F_{p}(\mathrm{~N})$ & $s F_{p}(\mathrm{~N})$ \\
\hline 1 & 0 & 411.60 & 27.92 & 357.02 & 28.68 & 257.63 & 20.75 & 116.36 & 12.62 \\
\hline 2 & 30 & 875.61 & 21.90 & 811.14 & 31.61 & 416.44 & 28.73 & 141.90 & 15.77 \\
\hline 3 & 60 & 1023.52 & 36.92 & 887.38 & 26.57 & 607.88 & 23.22 & 190.89 & 13.85 \\
\hline 4 & 90 & 511.06 & 26.47 & 462.24 & 28.08 & 308.73 & 22.23 & 174.91 & 19.37 \\
\hline 5 & 90 & 581.46 & 39.53 & 522.78 & 44.86 & 338.13 & 25.67 & 188.79 & 19.45 \\
\hline 6 & 90 & 604.98 & 25.09 & 540.45 & 21.80 & 340.62 & 22.30 & 176.42 & 26.12 \\
\hline 7 & 90 & 815.52 & 45.99 & 703.83 & 47.29 & 468.32 & 26.25 & 184.96 & 21.93 \\
\hline 8 & 90 & 821.07 & 28.18 & 697.77 & 24.98 & 491.92 & 26.41 & 183.51 & 22.84 \\
\hline 9 & 120 & 472.69 & 19.74 & 408.87 & 23.60 & 326.00 & 27.02 & 161.69 & 20.07 \\
\hline 10 & 150 & 380.60 & 22.47 & 316.64 & 23.44 & 243.62 & 18.49 & 140.77 & 21.21 \\
\hline
\end{tabular}

For conventional milling unidirectional CFRP, it is advisable to design the machining technology to a fibre orientation angle of $\phi_{\mathrm{opt}}=156^{\circ}$ in order to minimise cutting force.

\subsection{Comparison and discussion}

Based on the experimental results, it can be stated that (i) the fibre orientation angle significantly influences the cutting force. (ii) The cutting force as a function of the fibre orientation angle has a minimum point when using both analysed milling strategies (up and down milling). (iii) The minimum cutting force location is not the same for up and down milling: $\phi_{\text {down }, \text { opt }}=123^{\circ}$ for down and $\phi_{\text {up }, \text { opt }}=156^{\circ}$ for up milling. The main cutting force of climb and conventional milling are expressed by Eqs. (8) and (9), respectively. The models were developed based on regression analysis and validated by graphical adequate analysis. The third-degree polynomial models are shown in Fig. 9.

$$
\begin{aligned}
F_{\text {down }}(\phi)= & 0.0006 \phi^{3}-0.129 \phi^{2}+2.4166 \phi \\
& +879.24, \phi \in[0 ; 180)
\end{aligned}
$$

$$
\begin{aligned}
F_{u p}(\phi)= & 0.0011 \phi^{3}-0.3307 \phi^{2}+24.7710 \phi \\
& +415.9001, \phi \in[0 ; 180)
\end{aligned}
$$

When designing the movement path (toolpath) for cutting force-optimised milling of quasi-homogeneous materials, the chip cross-section should be optimised primarily [51, 52]. In the case of UD-CFRP composite, due to the anisotropy, the direction of the reinforcing fibres also significantly influences the milling tool paths optimised for the force minimum, so it is advisable to take this into account when milling UD-CFRP. The cutting force is minimal at fibre orientation of $\phi_{\text {up,opt }}=$ $156^{\circ}$ and at $\phi_{\text {down }, o p t}=123^{\circ}$ in the case of up or down milling strategies are applied. One of the optimums can be set in current CAM systems to generate an optimised tool path for UD-CFRP milling, however, both parameters usually cannot be considered simultaneously in the CAM systems.

The built-in milling cycles of current CAM software are typically not suited for assigning different orientation angles to one-way and one-way parallel tool paths during the generation of time-optimised milling tool paths. Thus, for the
Fig. 8 Influence of fibre orientation angle on the components of the cutting force in the case of conventional milling unidirectional CFRP composite

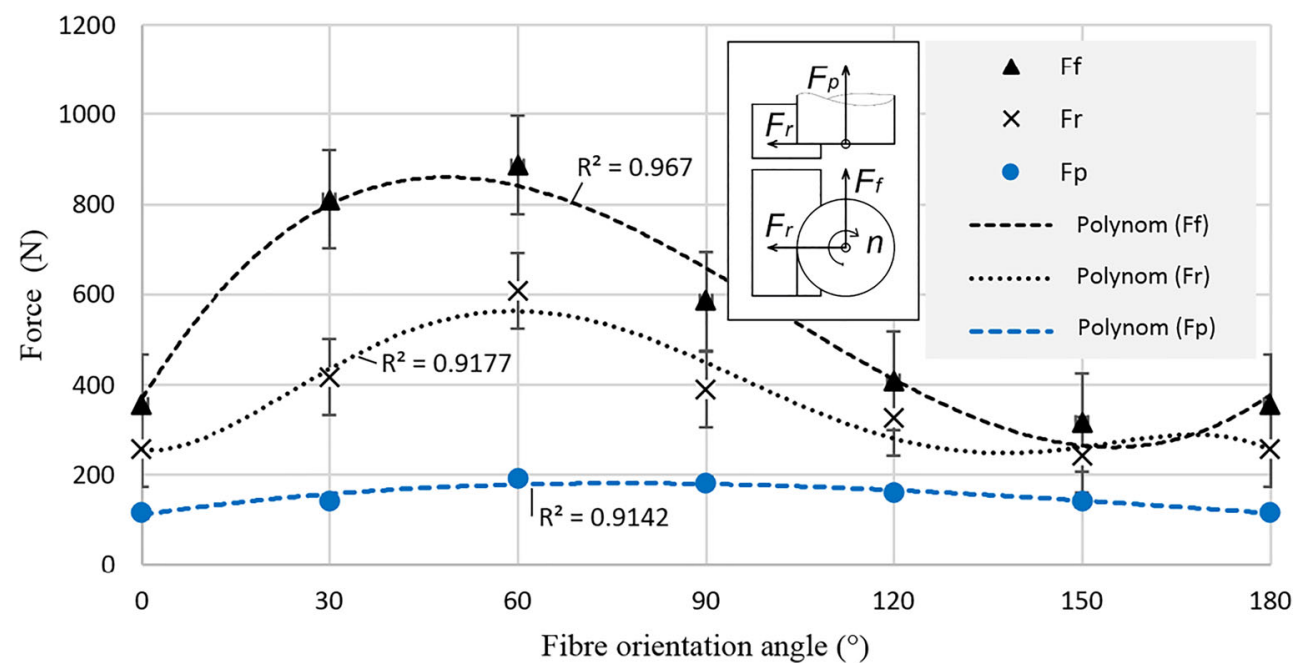


Fig. 9 Influence of fibre orientation angle on the main cutting force at up and down milling of unidirectional CFRP

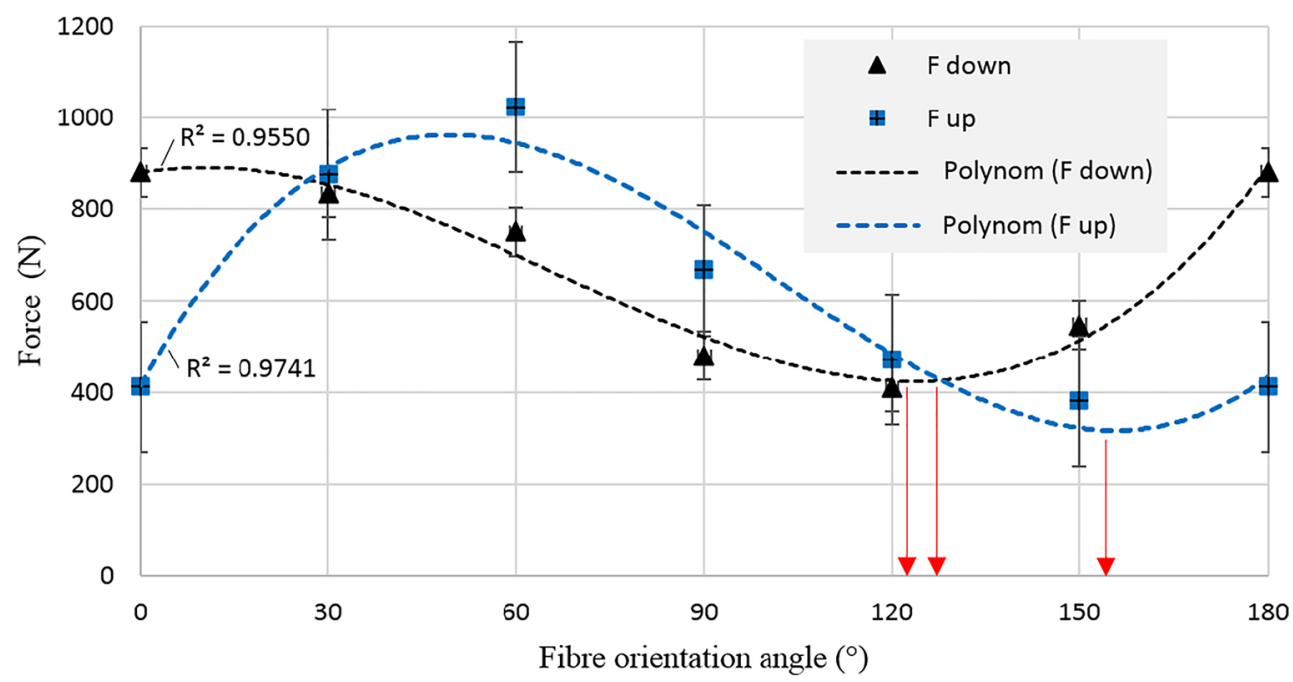

industrially efficient UD-CFRP milling zig-zag tool path design, it is suggested to use a $\phi_{\text {opt }}=128^{\circ}$ fibre orientation angle for cutting force minimisation (based on Fig. 9). Furthermore, novel tool paths are suggested to develop in order to create non-edge-parallel edge trimming cycles to avoid difficult-tocut fibre orientations like $\phi=0-90^{\circ}$ [53]. Cutting at the force minimum is a cardinal task for polymeric matrix composites, since (i) not only reducing the rate of tool wear, (ii) reducing heat generation due to frictional forces at the cutting edges (matrix burn), and (iii) reducing laminated layers. It can be also seen in the diagram (Fig. 9) that up milling produces smaller cutting force when the fibre orientation is set up between $\phi=23^{\circ}$ and $\phi=123^{\circ}$, while down milling produces smaller cutting force when the fibre orientation is lower than $\phi=23^{\circ}$ or bigger than $\phi=123^{\circ}$.
The chip removal mechanisms are analysed and discussed in detail in many scientific works [54-58]. Four different chip removal mechanisms are associated with machining unidirectional fibre reinforced polymers, defined based on the actual fibre cutting angle. The mechanisms are mostly dominated by bending-induced fractures (Type I: $\theta=0^{\circ} \pm \delta_{1}$ ), compression induced shear and interlaminar shear fractures (Type II: $\theta=45^{\circ}$ $\pm \delta_{2}$ and Type III: $\theta=90^{\circ} \pm \delta_{3}$ ) and macro fractures (Type IV: $\theta=135^{\circ} \pm \delta_{4}$ ).

Different chip removal mechanisms require different cutting energy, the cutting force at different fibre cutting angles are therefore different. In the case of a milling process, the fibre cutting angle is not a constant value and it changes with the tool position, as illustrated in

a)

Type II Type I

b)

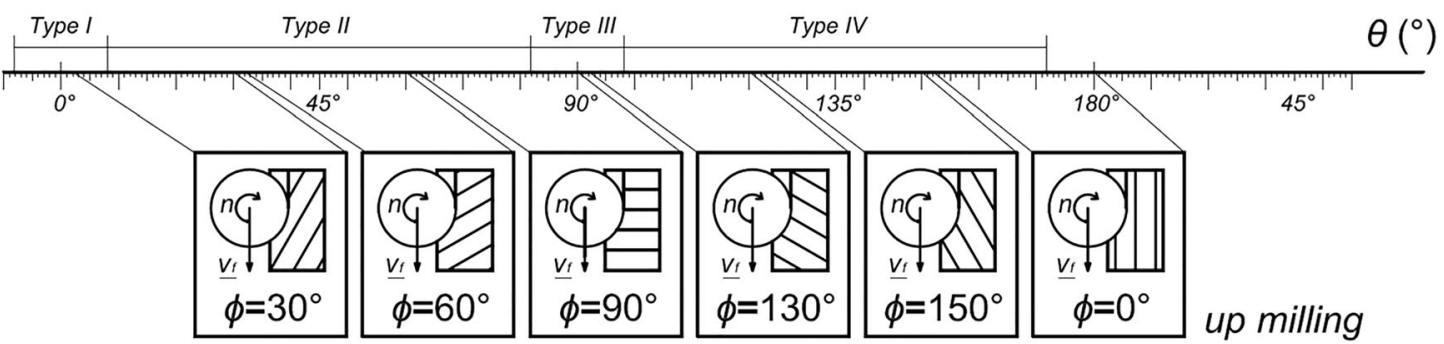

Fig. 10 Chip removal mechanisms associated with a down milling and $\mathbf{b}$ up milling of unidirectional CFRP at different fibre orientation angles $(\phi)$, where denotes the fibre cutting angle 
Fig. 10. It can be seen that at a certain set fibre orientation angle, the fibre cutting angle changes in a quite wide interval. The wideness of the interval depends on mainly the cutting width $\left(a_{e}\right)$ and the diameter of the tool $(D)$. In the present study, the diameter of the cutting tool was $D=50 \mathrm{~mm}$, while the cutting width was fixed to $a_{e}=3 \mathrm{~mm}$. In this case, the fibre cutting angle changes from (i) $\theta=28^{\circ}$ to $\theta=0^{\circ}$ in the case of down milling at $\phi=0^{\circ}$ and (ii) $\theta=58^{\circ}$ to $\theta=30^{\circ}$ in the case of down milling at $\phi=30^{\circ}$ etc., based on Fig. 10 .

In the future, the influence of cutting width has to be analysed on a minimum of three levels in order to extend the applicability range of the present study. Furthermore, future experiments should be conducted using a special compression end mill, which is widely used by the industries.

\section{Conclusions}

In the present study, machining experiments were carried out in a hand-laminated, thick, unidirectional CFRP in order to analyse the dependence of cutting force on the fibre orientation. According to the present study, the following conclusions can be drawn:

- Polynomial models were developed to analyse and describe the influence of the fibre orientation angle on cutting force for up and down milling unidirectional CFRP. The degree of the polynomials of the cutting force is calculated by regression analysis and validated by graphical adequate analysis.

- Experimental results showed that the fibre orientation angle significantly influences the cutting force in the case of up and down milling strategies were applied.

- It was observed that the fibre orientation does not have a significant effect on the passive force component during up and down milling; furthermore, the radial force component is more sensitive to the fibre orientation at up milling, than at down milling.

- It was found that the cutting force as a function of the fibre orientation angle has a minimum; however, the minimum cutting force location is not the same for up and down milling: $\phi_{\text {down }, \mathrm{opt}}=123^{\circ}$ for down and $\phi_{\text {up,opt }}=156^{\circ}$ for up milling when $D=50 \mathrm{~mm}$ and $a_{e}=3 \mathrm{~mm}$.

- Results of the regression analysis showed that a $\phi_{\text {opt }}=$ $128^{\circ}$ fibre orientation angle is suggested to be applied for cutting force minimisation for the industrially efficient UD-CFRP zig-zag tool path design.

- In the future, the influence of cutting width has to be analysed in order to extend the applicability range of the present study.
Funding Open access funding provided by Budapest University of Technology and Economics. This research was partly supported by the National Research, Development and Innovation Office (NKFIH) No. OTKA-PD20-134430 and by the project "Centre of Excellence in Production Informatics and Control" (EPIC) No. EU H2020WIDESPREAD-01-2016-2017-TeamingPhase2-739592. The research work introduced herein was partly supported by the Portugal-Hungarian bilateral scientific cooperation Project No. 2018-2.1.15-TÉT-PT-201800012 and by the BME NC TKP2020 grant of NKFIH Hungary.

Open Access This article is licensed under a Creative Commons Attribution 4.0 International License, which permits use, sharing, adaptation, distribution and reproduction in any medium or format, as long as you give appropriate credit to the original author(s) and the source, provide a link to the Creative Commons licence, and indicate if changes were made. The images or other third party material in this article are included in the article's Creative Commons licence, unless indicated otherwise in a credit line to the material. If material is not included in the article's Creative Commons licence and your intended use is not permitted by statutory regulation or exceeds the permitted use, you will need to obtain permission directly from the copyright holder. To view a copy of this licence, visit http://creativecommons.org/licenses/by/4.0/.

\section{References}

1. Szebényi G, Faragó D, Lámfalusi CS, Göbl R (2018) Interfacial adhesion improvement in carbon fiber/carbon nanotube reinforced hybrid composites by the application of a reactive hybrid resin initiated by gamma irradiation. Radiat Phys Chem 145:111-115. https://doi.org/10.1016/j.radphyschem.2017.12.018

2. Forintos N, Czigany T (Apr. 2019) Multifunctional application of carbon fiber reinforced polymer composites: electrical properties of the reinforcing carbon fibers - a short review. Compos Part B Eng 162:331-343. https://doi.org/10.1016/j.compositesb.2018.10.098

3. 'The Boeing company: https://www.boeing.com/commercial/ aeromagazine/articles/qtr_4_06/article_04_2.html'.

4. Davim JP (2013) Machining composites materials. John Wiley \& Sons

5. Abrão AM, Faria PE, Rubio JCC, Reis P, Davim JP (May 2007) Drilling of fiber reinforced plastics: a review. J Mater Process Technol 186(1):1-7. https://doi.org/10.1016/j.jmatprotec.2006. 11.146

6. Geier N, Paulo Davim J, Szalay T (2019) Advanced cutting tools and technologies for drilling carbon fibre reinforced polymer (CFRP) composites: a review. Compos Part A 125:105552. https://doi.org/10.1016/j.compositesa.2019.105552

7. Krishnaraj V, Zitoune R, Davim JP (2013) Drilling of polymermatrix composites. Springer Berlin Heidelberg, Berlin, Heidelberg

8. Ashworth S, Fairclough JPA, Takikawa Y, Scaife R, Ghadbeigi H, Kerrigan K, Meredith J (2019) Effects of machine stiffness and cutting tool design on the surface quality and flexural strength of edge trimmed carbon fibre reinforced polymers. Compos Part Appl Sci Manuf 119:88-100. https://doi.org/10.1016/j. compositesa.2019.01.019

9. Duboust N, Pinna C, Ghadbeigi H, Ayvar-Soberanis S, Phadnis VA, Collis A, Kerrigan K (2017) 2D and 3D finite element models for the edge trimming of CFRP. Procedia CIRP 58:233-238. https://doi.org/10.1016/j.procir.2017.03.217

10. Pereszlai C, Geier N (2020) Comparative analysis of wobble milling, helical milling and conventional drilling of CFRPs. Int J Adv Manuf Technol 106(9):3913-3930. https://doi.org/10.1007/ s00170-019-04842-4 
11. Wang Q, Wu Y, Bitou T, Nomura M, Fujii T (2018) Proposal of a tilted helical milling technique for high quality hole drilling of CFRP: kinetic analysis of hole formation and material removal. Int J Adv Manuf Technol 94(9):4221-4235. https://doi.org/10. 1007/s00170-017-1106-3

12. Schulze V, Spomer W, Becke C (2012) A voxel-based kinematic simulation model for force analyses of complex milling operations such as wobble milling. Prod Eng 6(1):1-9. https://doi.org/10.1007/ s11740-011-0348-4

13. Davim JP, Reis P (2003) Study of delamination in drilling carbon fiber reinforced plastics (CFRP) using design experiments. Compos Struct 59(4):481-487. https://doi.org/10.1016/S02638223(02)00257-X

14. Kerrigan K, Scaife RJ (2018) Wet vs dry CFRP drilling: influence of cutting fluid on tool performance. Procedia CIRP 77:315-319. https://doi.org/10.1016/j.procir.2018.09.024

15. Xu J, Li C, Dang J, El Mansori M, Ren F (2018) A Study on Drilling High-Strength CFRP Laminates: Frictional Heat and Cutting Temperature. Materials 11(12):12. https://doi.org/10. 3390/ma11122366

16. Abhishek K, Datta S, Mahapatra SS (2015) Optimization of thrust, torque, entry, and exist delamination factor during drilling of CFRP composites. Int J Adv Manuf Technol 76(1):401-416. https://doi. org/10.1007/s00170-014-6199-3

17. Al-wandi S, Ding S, Mo J (2017) An approach to evaluate delamination factor when drilling carbon fiber-reinforced plastics using different drill geometries: experiment and finite element study. Int J Adv Manuf Technol 93(9):4043-4061. https://doi.org/10.1007/ s00170-017-0880-2

18. Geier N, Szalay T (2017) Optimisation of process parameters for the orbital and conventional drilling of uni-directional carbon fibrereinforced polymers (UD-CFRP). Measurement 110:319-334. https://doi.org/10.1016/j.measurement.2017.07.007

19. Geier N, Póka G, Szalay T (2018) Direct monitoring of hole damage in carbon fibre-reinforced polymer (CFRP) composites. IOP Conf Ser Mater Sci Eng 448(1):012003. https://doi.org/10.1088/ 1757-899X/448/1/012003

20. Haddad M, Zitoune R, Eyma F, Castanie B (2014) Study of the surface defects and dust generated during trimming of CFRP: influence of tool geometry, machining parameters and cutting speed range. Compos Part Appl Sci Manuf 66:142-154. https://doi.org/ 10.1016/j.compositesa.2014.07.005

21. Gara S, Tsoumarev O (2016) Prediction of surface roughness in slotting of CFRP. Measurement 91:414-420. https://doi.org/10. 1016/j.measurement.2016.05.016

22. Abhishek K, Datta S, Mahapatra SS (2016) Multi-objective optimization in drilling of CFRP (polyester) composites: application of a fuzzy embedded harmony search (HS) algorithm. Measurement 77: 222-239. https://doi.org/10.1016/j.measurement.2015.09.015

23. Geier N, Pereszlai C (2020) Analysis of characteristics of surface roughness of machined CFRP composites. Period Polytech Mech Eng 64(1):67-80. https://doi.org/10.3311/PPme.14436

24. Geier N, Póka G, Pereszlai C (2019) Monitoring of orbital drilling process in CFRP based on digital image processing of characteristics of uncut fibres. Procedia CIRP 85:165-170. https://doi.org/10. 1016/j.procir.2019.09.011

25. Cepero-Mejías F, Curiel-Sosa JL, Blázquez A, Yu TT, Kerrigan K, Phadnis VA (2020) Review of recent developments and induced damage assessment in the modelling of the machining of long fibre reinforced polymer composites. Compos Struct 240:112006. https://doi.org/10.1016/j.compstruct.2020.112006

26. Xu J, Li C, Mi S, An Q, Chen M (2018) Study of drilling-induced defects for CFRP composites using new criteria. Compos Struct 201:1076-1087. https://doi.org/10.1016/j.compstruct.2018.06.051

27. Wan M, Li S-E, Yuan H, Zhang W-H (2019) Cutting force modelling in machining of fiber-reinforced polymer matrix composites
(PMCs): a review. Compos Part Appl Sci Manuf 117:34-55. https://doi.org/10.1016/j.compositesa.2018.11.003

28. Davim JP, Reis P (2003) Drilling carbon fiber reinforced plastics manufactured by autoclave - experimental and statistical study. Mater Des 24(5):315-324. https://doi.org/10.1016/S02613069(03)00062-1

29. Jáuregui JC, Reséndiz JR, Thenozhi S, Szalay T, Jacsó Á, Takács $M(2018)$ Frequency and time-frequency analysis of cutting force and vibration signals for tool condition monitoring. IEEE Access 6: 6400-6410. https://doi.org/10.1109/ACCESS.2018.2797003

30. Biró I, Szalay T (2017) Extension of empirical specific cutting force model for the process of fine chip-removing milling. Int J Adv Manuf Technol 88(9):2735-2743. https://doi.org/10.1007/s00170016-8957-x

31. Biró I, Szalay T, Geier N (2018) Effect of cutting parameters on section borders of the empirical specific cutting force model for cutting with micro-sized uncut chip thickness. Procedia CIRP 77: 279-282. https://doi.org/10.1016/j.procir.2018.09.015

32. Biró I, Czampa M, Szalay T (2015) Experimental model for the Main cutting force in face milling of a high strength structural steel. Period Polytech Mech Eng 59(1):16-22. https://doi.org/10.3311/ PPme.7516

33. Krolczyk GM, Legutko S (2014) Experimental analysis by measurement of surface roughness variations in turning process of duplex stainless steel. Metrol Meas Syst 21(4):759-770. https://doi. org/10.2478/mms-2014-0060

34. Krolczyk G, Legutko S, Stoić A (2013) Influence of cutting parameters and conditions onto surface hardness of duplex stainless steel after turning process. Teh Vjesn 20(6):1077-1080

35. Su F, Yuan J, Sun F, Wang Z, Deng Z (2018) Analytical cutting model for a single fiber to investigate the occurrences of the surface damages in milling of CFRP. Int J Adv Manuf Technol 96(5-8): 2671-2685. https://doi.org/10.1007/s00170-018-1797-0

36. Li H, Qin X, He G, Jin Y, Sun D, Price M (2016) Investigation of chip formation and fracture toughness in orthogonal cutting of UDCFRP. Int J Adv Manuf Technol 82(5):1079-1088. https://doi.org/ 10.1007/s00170-015-7471-x

37. Voss R, Seeholzer L, Kuster F, Wegener K (2017) Influence of fibre orientation, tool geometry and process parameters on surface quality in milling of CFRP. CIRP J Manuf Sci Technol 18:75-91. https://doi.org/10.1016/j.cirpj.2016.10.002

38. He Y, Qing H, Zhang S, Wang D, Zhu S (2017) The cutting force and defect analysis in milling of carbon fiber-reinforced polymer (CFRP) composite. Int J Adv Manuf Technol 93(5-8):1829-1842. https://doi.org/10.1007/s00170-017-0613-6

39. Sui J, Wang C (2018) Machinability study of unidirectional CFRP laminates by slot milling. In: Int. J. Adv. Manuf. Technol. https:// doi.org/10.1007/s00170-018-2730-2

40. Slamani M, Gauthier S, Chatelain J-F (2015) A study of the combined effects of machining parameters on cutting force components during high speed robotic trimming of CFRPs. Measurement 59: 268-283. https://doi.org/10.1016/j.measurement.2014.09.052

41. Li H, Qin X, Huang T, Liu X, Sun D, Jin Y (2018) Machining quality and cutting force signal analysis in UD-CFRP milling under different fiber orientation. Int J Adv Manuf Technol 98(9):23772387. https://doi.org/10.1007/s00170-018-2312-3

42. Xu J, An Q, Cai X, Chen M (2013) Drilling machinability evaluation on new developed high-strength T800S/250F CFRP laminates. Int J Precis Eng Manuf 14(10):1687-1696. https://doi.org/10.1007/ s12541-013-0252-2

43. Xu J, Li C, Chen M, El Mansori M, Ren F (2019) An investigation of drilling high-strength CFRP composites using specialized drills. Int J Adv Manuf Technol 103(9):3425-3442. https://doi.org/10. 1007/s00170-019-03753-8

44. Wang C, Liu G, An Q, Chen M (2017) Occurrence and formation mechanism of surface cavity defects during orthogonal milling of 
CFRP laminates. Compos Part B Eng 109:10-22. https://doi.org/ 10.1016/j.compositesb.2016.10.015

45. Wang H, Sun J, Li J, Lu L, Li N (2016) Evaluation of cutting force and cutting temperature in milling carbon fiber-reinforced polymer composites. Int J Adv Manuf Technol 82(9):1517-1525. https:// doi.org/10.1007/s00170-015-7479-2

46. Karpat Y, Polat N (2013) Mechanistic force modeling for milling of carbon fiber reinforced polymers with double helix tools. CIRP Ann 62(1):95-98. https://doi.org/10.1016/j.cirp.2013.03.105

47. Masek P, Zeman P, Kolar P, Holesovsky F (2019) Edge trimming of C/PPS plates. Int J Adv Manuf Technol 101(1):157-170. https:// doi.org/10.1007/s00170-018-2857-1

48. Slimane A, Slimane S, Kebdani S, Chaib M, Dahmane S, Bouchouicha B, Sardi N, Adjim S (Jun. 2019) Parameters effects analysis of rotary ultrasonic machining on carbon fiber reinforced plastic (CFRP) composite using an interactive RSM method. Int J Interact Des Manuf IJIDeM 13(2):521-529. https://doi.org/10. 1007/s12008-018-0518-0

49. Tripathi VK, Ambekar S (2019) Optimization and Analysis of Wear Rate of CFRP-NanoZno/Nanoclay Hybrid Composites Using RSM. J Bio- Tribo-Corros 5(4):96. https://doi.org/10.1007/ s40735-019-0284-y

50. Monostori L (2014) Cyber-physical production systems: roots, expectations and R\&D challenges. Procedia CIRP 17:9-13. https:// doi.org/10.1016/j.procir.2014.03.115

51. Jacso A, Szalay T (2018) Analysing and Optimizing 2.5D Circular Pocket Machining Strategies. In: Advances in Manufacturing, pp 355-364
52. Jacso A, Szalay T, Jauregui JC, Resendiz JR (2019) A discrete simulation-based algorithm for the technological investigation of 2.5D milling operations. Proc Inst Mech Eng Part C J Mech Eng Sci 233(1):78-90. https://doi.org/10.1177/0954406218757267

53. Geier N, Szalay T, Biró I (2018) Trochoid milling of carbon fibrereinforced plastics (CFRP). Procedia CIRP 77:375-378. https://doi. org/10.1016/j.procir.2018.09.039

54. J. Ahmad, Machining of polymer composites. Springer US, 2009

55. Calzada KA, Kapoor SG, DeVor RE, Samuel J, Srivastava AK (Apr. 2012) Modeling and interpretation of fiber orientation-based failure mechanisms in machining of carbon fiber-reinforced polymer composites. J Manuf Process 14(2):141-149. https://doi.org/ 10.1016/j.jmapro.2011.09.005

56. Su Y (Jul. 2019) Effect of the cutting speed on the cutting mechanism in machining CFRP. Compos Struct 220:662-676. https://doi. org/10.1016/j.compstruct.2019.04.052

57. Yan X, Reiner J, Bacca M, Altintas Y, Vaziri R (Jul. 2019) A study of energy dissipating mechanisms in orthogonal cutting of UDCFRP composites. Compos Struct 220:460-472. https://doi.org/ 10.1016/j.compstruct.2019.03.090

58. Geier N, Szalay T, Takács M (Oct. 2018) Analysis of thrust force and characteristics of uncut fibres at non-conventional oriented drilling of unidirectional carbon fibre-reinforced plastic (UD-CFRP) composite laminates. Int J Adv Manuf Technol 100(9-12):31393154. https://doi.org/10.1007/s00170-018-2895-8

Publisher's note Springer Nature remains neutral with regard to jurisdictional claims in published maps and institutional affiliations. 